\title{
Numerical Simulation of Heat exchanger for analyzing the performance of parallel and counter flow
}

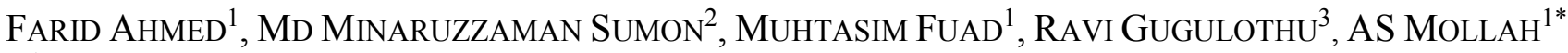 \\ ${ }^{1}$ Department of Nuclear Science and Engineering, Military Institute of Science and Technology, \\ Dhaka, BANGLADESH. \\ ${ }^{2}$ Department of Mechanical Engineering, Bangladesh University of Engineering and Technology, \\ Dhaka, BANGLADESH. \\ ${ }^{3}$ Department of Mechanical Engineering, JNTUH College of Engineering Hyderabad, Kukatpally, \\ INDIA
}

\begin{abstract}
Heat exchangers are almost used in every industry. Among them, shell and tube heat exchangers are covering around $32 \%$ of the total heat exchanger. Numerical simulation of the Computational models is playing an important role for the prototypes including the Heat Exchanger Models for the improvement in modeling. In this study, the CFD analysis of parallel and counter flow shell and tube heat exchanger was performed.

Following project, looked into the several aspects and these are the temperature, velocity, and pressure drop and turbulence kinetic energy along with the heat exchanger length. Hot water was placed in tube side and cold water was placed in shell side of the heat exchanger. Shell side cold temperature was increasing along the heat exchanger length. On the other side, tube side hot water temperature was decreasing along the tube length. This effect was more significance in counter flow rather than the parallel flow. Velocity was more fluctuating in the shell side due to presence of the baffles. Also following the same reason, pressure drop was higher in the shell side cold water rather than the tube side hot water. To measure the turbulence effect, turbulence kinetic energy was determined. Turbulence was decreasing first part of the shell and tube heat exchanger. But, it was increasing along through the rest part heat exchanger. All these observations and the outcomes are evaluated and then further analyzed.
\end{abstract}

Key-Words: -Numerical Simulation, ANSYS Fluent, Heat Exchanger.

Received: April 12, 2021. Revised: August 16, 2021. Accepted: September 1, 2021. Published: September 20, 2021. 


\section{Introduction}

Heat exchanger is a device which can transfer heat between two or more fluids from higher temperature to lower temperature. Various types of heat exchangers are used for process of heating and cooling applications[1]. In many engineering sectors heat exchangers are playing major role, due to reliability, technology involved in manufacturing methods, versatility of it and operating at high pressure and temperatures[2]. Since many years, industries like oil refinery, power generation plants are using shell and tube heat exchangers, in it baffles plays the key component to leads the fluid flow in shell area.

The characteristics of the fluid flow and the temperature profile of the fluid once the wall temperature changes, is completely dependent on the fluid properties due to wall temperature. Similarly the velocity profile can also be developed which is used for any Prandtl number material. The only assumption here is to make sure that both the temperature and the pressure profiles are starting at the same point [3]. The velocity field of the fluid that is flowing through the wall temperature tubing was described based on the Poiseuille flow which was assumed based on the analytical measurements [4]. The developed solutions by Sellars, Tribus and Klein [5][6][7][8], the entrance of the tubingfor the series solution had extremely low convergence. Hwang et al. [7] computed the coefficient of the heat transfer along with the pressure drop in the developed laminar pipe flow maintaining the constant heat flow conditions. It was evaluated and then further discussed that the result of experimental analysis matches with the prediction from theoretical calculation precisely. Bianco[8], detected a supreme of $11 \%$ variation between the single and the double laminar phase regime.

Akbari et al. [9], then analyzed the results of two phase and single phase fluid flow regime under laminar flow condition for three different fluid models. The study concluded that both the single phase and double phase flow regime models are capable to produce identical features of hydrodynamic properties. The term hydro dynamically developed flow is achieved in a pipe where the effect of velocity from the entrance length reaches the center of the pipe.

Currently, new heat exchangers have also been considered for the development in the field of thermal engineering such as the small heat exchangers which are used for the cooling of the electronic components and the systems $[9][10][11][12][13]$. Some new materials such as polymers have also been discovered for improving polymer heat exchanger for better entanling and also resistance to corrosion[14]. Kragh et al. [15] also developed a new counter flow heat exchanger for the ventilation system for the colder climates. The efficiency of the heat exchanger was then calculated both experimentally and theoretically. For analyzing the impact of the operational and the geometric parameters of the cross flow and the counter flow heat exchangers on different cooling performances, Zhan et al. [16] developed and used an experimentally validated model. Later, Hasan et al.[17], showed the effect of channel geometry on the counter flow heat changer performance. Different shapes such as the circular, square, rectangular, etc were evaluated by the used numerical simulations and the influences of these shapes were studied. They conferred from their studies that up surging the channel numbers eventually enhanced the heat transfer but the pressure and the pumping power got enlarged. The conclusion was made that the circular shaped tubes are capable of resulting an increase under optimum conditions compared to other types of shapes [18].

Hamid Reza Abbasi et al. [1] numerically studied shell and tube heat exchanger with segmental baffles with porous media using CFD in combination with machine learning tools, author noticed that baffle angle 111.90 and $16.69 \mathrm{~mm}$ thickness baffle is the optimum configuration to produce $523.81 \mathrm{~kW}$ heat transfer rate, $48.87 \mathrm{kPa}$ pressure drop. It reduces $61.3 \%$ pressure drop and $11.15 \%$ enhancement in heat transfer. HasanKucuk et al. [28] experimentally investigated the heat transfer and pressure drop of shell and tube heat exchanger using Kern's method with $25 \%$ baffle cut, 2.3 times higher pressure drop.

In this paper, the investigation was made to highlight the performance of counter flow over parallel flow for transferring heat. The results of numerical simulation were compared with both the analytical and experimental results. The objective of the study is to show the capacity of removing heat for counter flow over turbulent flow including the observation of flow profile and pressure drop. For the purpose of this project is to introduce the undergraduate students with CFD simulations of Heat Exchanger and validating the CFD results with the experimental data acquired from laboratory. The study could be a necessary and fundamental approach to accomplish for undergraduate students studying heat transfers in heat exchanger.

\section{Governing Equations}

Finite volume method was considered for solving the governing equations of CFD model using ANSYS Fluent [22]. FVM is a discretization techniques to discretize Partial Differential Equations which is widely popular for capturing flow physics of complex fluid and complex geometries [23]. However, FVM techniques require more computational efforts. The properties for the coolant water are kept to be constant and the flow is considered to be incompressible, whereas water is assumed to be a Newtonian fluid. Over the flow regime, under completely steady conditions, for analyzing the temperature and velocity fields Navier-Stokes equation, energy equations, are solved for the continuity of fluid. The governing equations over the flow regime are showed[24]:

Continuity equation:

$\frac{\partial\left(\rho u_{i}\right)}{\partial x_{i}}=0$ 
Momentum equation:

$$
\frac{\partial\left(\rho u_{i} u_{k}\right)}{\partial x_{i}}=\frac{\partial\left(\mu \frac{\partial u_{k}}{\partial x_{i}}\right)}{\partial x_{i}}-\frac{\partial p}{\partial x_{k}}
$$

Energy Equation:

$$
\frac{\partial\left(\rho u_{i} t\right)}{\partial x_{i}}=\frac{\partial\left(\frac{k}{C_{p}} \frac{\partial t}{\partial x_{i}}\right)}{\partial x_{i}}
$$

Turbulent kinetic energy equation:

$$
\frac{\partial(\rho k)}{\partial t}+\frac{\partial\left(\rho k u_{i}\right)}{\partial x_{i}}=\frac{\partial\left(\frac{\alpha_{k} \mu_{e f f} \partial k}{\partial x_{j}}\right)}{\partial x_{j}}+G_{k}+\rho \varepsilon
$$

Turbulent dissipation energy equation:

$\frac{\partial(\rho \varepsilon)}{\partial t}+\frac{\partial\left(\rho u_{i}\right)}{\partial x_{i}}=\frac{\partial\left(\frac{\alpha \varepsilon \mu_{e f f} \partial \varepsilon}{\partial x_{j}}\right)}{\partial x_{j}}+\frac{G_{k} \varepsilon C_{1 \varepsilon}^{*}}{k}-\frac{C_{2 \varepsilon} \varepsilon^{2} \rho}{k}$

Where, $\mu_{e f f}=\mu+\mu_{t}, \quad \mu_{t}=\rho c_{\mu} \frac{k^{2}}{\varepsilon}$,

$C_{1 \varepsilon}^{*}=C_{1 \varepsilon}-\frac{\eta\left(1-\frac{\eta}{\eta_{0}}\right)}{1+\beta \eta^{3}}, \eta=\left(2 E_{i j} \cdot E_{i j}\right)^{0.5} \frac{k}{\varepsilon}$,

$E_{i j}=0.5\left\lfloor\frac{\partial u_{i}}{\partial x_{j}}+\frac{\partial u_{j}}{\partial x_{i}}\right\rfloor$

The observed constants for the RNG, k- $\varepsilon$ model are assigned as follows:

$C_{\mu}=\frac{845}{10,000}, \quad C_{1 \varepsilon}=\frac{142}{100}, \quad C_{2 \varepsilon}=\frac{168}{100}, \quad \beta=\frac{12}{1000}$,

$\eta_{0}=\frac{438}{100}, \alpha_{k}=\alpha_{\varepsilon}=\frac{139}{100}$

\section{Computational Model}

Table 1. Design features for the study of shell and tube heat exchanger

\begin{tabular}{|l|c|}
\hline Major Design Features & Dimensions \\
\hline Heat exchanger length, $\mathrm{L}$ & $600 \mathrm{~mm}$ \\
\hline Inner diameter of shell, Ds & $90 \mathrm{~mm}$ \\
\hline Length of the tube, 1 & $600 \mathrm{~mm}$ \\
\hline $\begin{array}{l}\text { Outer diameter of the tube, } \\
\mathrm{D}_{\mathrm{O}}\end{array}$ & $20 \mathrm{~mm}$ \\
\hline No of tube, $\mathrm{Nt}$ & 07 \\
\hline Tube pitch \& geometry, $\mathrm{Pt}$ & $\begin{array}{l}\text { Triangula } \\
\text { r, } 30 \mathrm{~mm}\end{array}$ \\
\hline Baffle cut, $\mathrm{Bc}$ & $25 \%$ \\
\hline Baffle spacing, $\mathrm{B} \mathrm{S}$ & $85.70 \mathrm{~mm}$ \\
\hline Baffle thickness, $\mathrm{t}$ & $3 \mathrm{~mm}$ \\
\hline No of buffles, Nb & 6 \\
\hline Baffle inclination, $\alpha$ & 0 degree \\
\hline
\end{tabular}

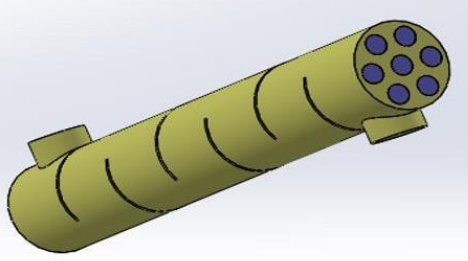

Figure 1. Geometry of Computational Domain

\section{Meshing and Grid Generation}

The grid generations were taken into consideration with different mesh refinement ratios through changing the number of nodes and element sizes. The grid generations started with a coarse mesh with tetrahedral and pyramid shaped cells along with triangular and quadrilateral face. The connection between the nodes and elements over the contact regions and interfaces are maintained through contact meshing. The accuracy was maintained through creating polyhedral meshes using reverse cut cell method over the shell domain region[25][26][27]. Finally the elements and nodes are shell domain region. Finally the elements and nodes are bounded with 1757548 and 587849 respectively (Figure-3). The numerical diffusion is reduced through creating concentrated mesh near wall region and the wall treatment was enhanced through creating inflation layer to capture both the thermal and velocity gradient during fluid flow. 


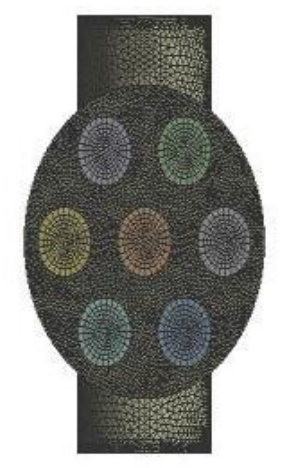

Figure 2: Grid generation over flow regime

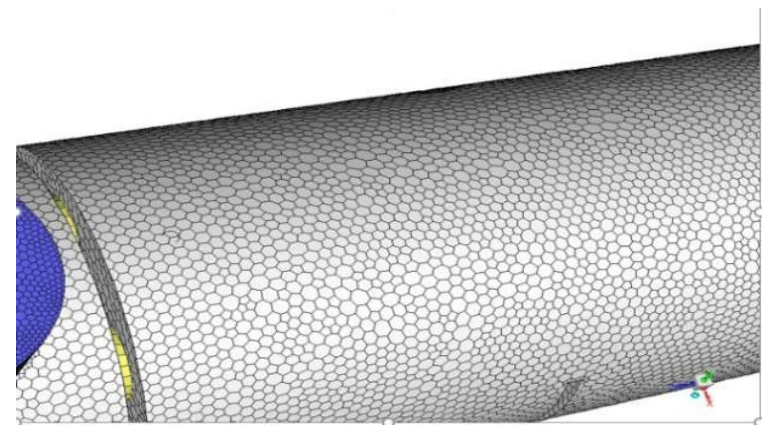

Figure 3. Polyhedral mesh over flow regime

\section{Boundary Conditions}

For producing fully developed turbulent flow the flow channel was kept to be $600 \mathrm{~mm}$ which is sufficient for creating fully developed turbulent flow. For solving the turbulent nature RNG k-epsilon model was chosen. The inlet velocity is kept $1.594 \mathrm{~m} / \mathrm{s}$ for the hot channel whereas the outlet is considered to be pressure outlet. The inlet velocity for cold channel is chosen to be $0.0787 \mathrm{~m} / \mathrm{s}$ and outlet is assumed as pressure outlet. The temperature of the hot water is chosen to be $340 \mathrm{~K}$ while the temperature of the coolant is selected as $300 \mathrm{~K}$. The surrounding temperature of the environment including the temperature of tube wall is kept to be $300 \mathrm{~K}$.

\section{Numerical Simulations}

For solving the coupling of pressure and velocity fields SIMPLEC mechanism is selected having a zero correction for the skewness of the cell. For getting better accuracy, second order upwind was enabled for both the energy and momentum equations during the spatial discretization using Finite Volume Method. The convergence criteria were set to e-6 for continuity and momentum equations while e-8 is kept for energy equations. The simulation was progressed using ANSYS Fluent.

\section{Validations of the Results}

For the validation of the numerical results both the experimental analysis and the analytical approach is formulated. For the convenience of the validation variation of temperature is calculated from the experimental set up as well as from the analytical solution. The variation of temperature for both the counter flow and parallel flow over the computational domain is tabulated in Table 2 and Table 3.

Table 2

\begin{tabular}{|l|c|c|c|}
\hline $\begin{array}{l}\text { Fluid } \\
\text { Domain } \\
\text { Analysis }\end{array}$ & $\begin{array}{c}\text { Analytical } \\
\text { Results }(\Delta \mathbf{T}) \\
\text { Kelvin }\end{array}$ & $\begin{array}{c}\text { Experimental } \\
\text { Results }(\Delta \mathbf{T}) \\
\text { Kelvin }\end{array}$ & $\begin{array}{c}\text { Present } \\
\text { Study } \\
(\mathbf{\Delta T}) \\
\text { Kelvin }\end{array}$ \\
\hline $\begin{array}{c}\text { Temperature } \\
\text { change } \\
\text { in hot } \\
\text { water }\end{array}$ & 2.70 & 2.75 & 2.53 \\
\hline $\begin{array}{c}\text { Temperature } \\
\text { change in } \\
\text { cold water }\end{array}$ & 7.22 & 7.26 & 7.0 \\
\hline
\end{tabular}

Table 3

\begin{tabular}{|l|c|c|c|}
\hline $\begin{array}{l}\text { Fluid } \\
\text { Domain } \\
\text { Analysis }\end{array}$ & $\begin{array}{c}\text { Analytical } \\
\text { Results }(\Delta \mathbf{\Delta}) \\
\text { Kelvin }\end{array}$ & $\begin{array}{c}\text { Experimental } \\
\text { Results }(\Delta \mathbf{\Delta T}) \\
\text { Kelvin }\end{array}$ & $\begin{array}{c}\text { Present } \\
\text { Study } \\
(\mathbf{\Delta T}) \\
\text { Kelvin }\end{array}$ \\
\hline $\begin{array}{l}\text { Temperature } \\
\text { change in } \\
\text { hot water }\end{array}$ & 4.279 & 4.3 & 4.53 \\
\hline $\begin{array}{l}\text { Temperature } \\
\text { change in cold } \\
\text { water }\end{array}$ & 14.44 & 14.5 & 14.9 \\
\hline
\end{tabular}

\section{Results and Discussion}

For the analysis and evaluation of the performance of heat exchanger various parameters was analyzed like temperature contour, pressure drop, velocity contour, and turbulence kinetic energy.

\subsection{Heat Transfer}

From the Figure 4 the evaluation can be made that the counter flow of the fluid direction over the domain efficiently increases the heat transfer. The change of the temperature along the centerline was investigated and found that the counter flow transfer more heats as the graphical line goes farther down compared to parallel flow. Besides from the Table 2 and 3 , it can be concluded that the variation of temperature for both the hot fluid and cold fluid over the fluid domain is sufficiently high for counter flow compared to parallel flow. The centerline temperatures are taken over the hot flow regime. Figure 5 shows the temperature variation over the wall of hot tubes to evaluate the extraction of temperature through the coolant. 


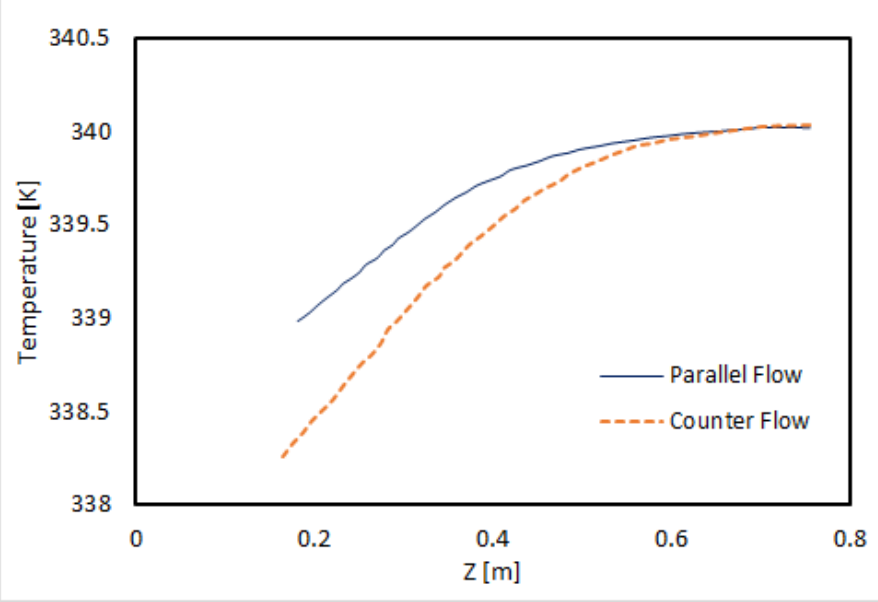

Figure 4: Temperature distribution along the centreline of the shell and tube heat exchanger

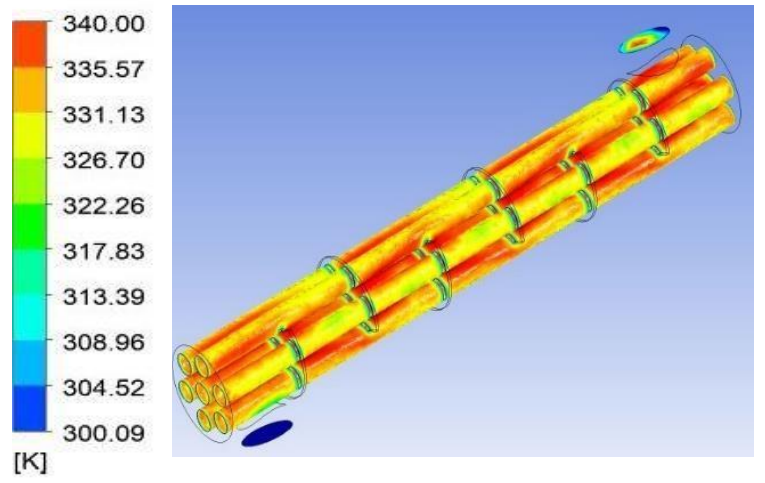

Figure 5: Temperature distribution over the hot tubes

\subsection{Variation of Pressure}

From Figure-6, the pressure drop for both type of heat exchanger is evaluated through pressure counter. It indicates that the pressure is decreasing along the coolant flow direction over the fluid domain which eventually increases the pressure drop. The pressure is dropped at the baffles and the inlet and outlet in the shell of the shell and tube heat exchanger. In the tube side hot water region pressure doesn't decrease significantly.

\subsection{Variation of Velocity}

Efficiencies of the shell and tube heat exchanger are largely depends on the velocity profile of the shell side cold water and the tube side hot water. Figure 7 indicates that tube side hot water velocity can't change significantly. But it indicates that the shell side cold water velocity can change with irregular manner. From the Bernoulli's Equation, that summation of kinetic head, static pressure head and potential head is constant [19][20][21][24].

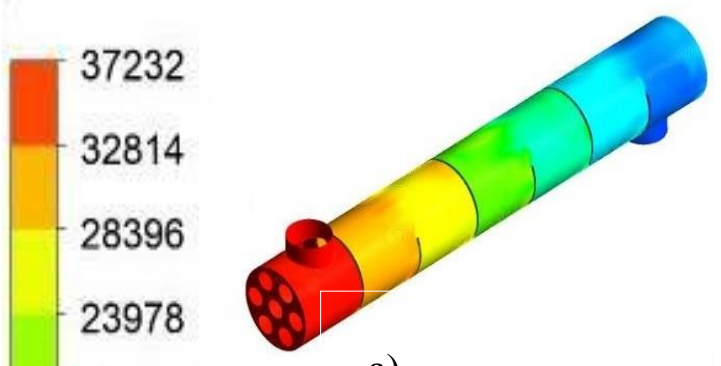

a)

19560

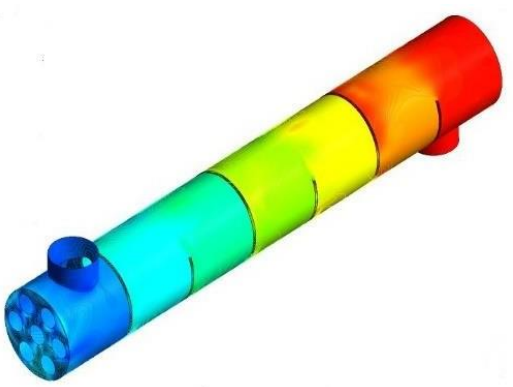

$-2530$

$[\mathrm{Pa}]$

b)

Figure 6: Pressure variation of shell and tube side water along the heat exchanger in (a) Parallel flow (b) Counter flow

\subsection{Variation of Velocity}

Efficiencies of the shell and tube heat exchanger are largely depends on the velocity profile of the shell side cold water and the tube side hot water. Figure 7 indicates that tube side hot water velocity can't change significantly. But it indicates that the shell side cold water velocity can change with irregular manner. From the Bernoulli's Equation, that summation of kinetic head, static pressure head and potential head is constant [19][20][21][24]. In other words, summation of static pressure energy, kinetic energy and potential energy is constant. As, for this model of the shell and tube heat exchanger's inlet and outlet are in same elevation, so the potential head is constant. Now, if the change in the pressure head changes, the kinetic head/velocity must change. At the baffle region of the shell and tube heat exchanger, pressure decreases. For this reason, velocity at the region increases. This approach can be explained in other ways using the continuity equation. According to the continuity equation, the mass flow rate of a control volume is always constant. At the baffle region in the shell of the shell and tube heat exchanger, there is less flow area. To ensure the mass flow rate constant at this region, velocity needs to increase. At this region, velocity increases several decades to hundreds. 

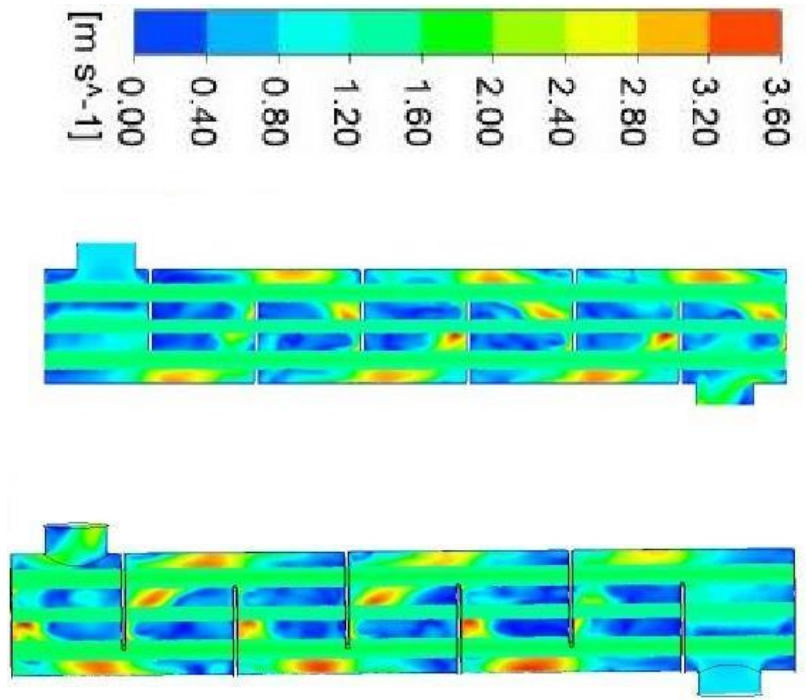

Figure 7: Velocity variation of shell and tube side water along the (a) parallel flow (b) counter flow in heat exchanger

Moreover, it is observed that the inlet velocity of the hot fluid starts to increase up to the cold fluid zone and again starts to decrease a bit. Though the hot fluid velocity should remain constant over the tubes but the velocity fluctuates because of the temperature changes in fluid which eventually leads to kinetics of the fluid molecules.

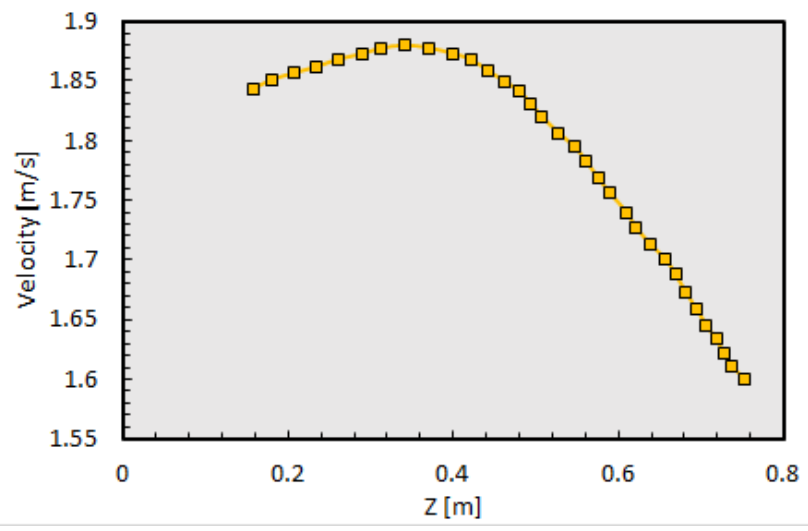

Figure 8: Velocity distribution along the centreline of the shell and tube heat exchanger (Counter Flow)

In this Figure 8, the water enters into the shell from the right. It means that the flow direction of the shell side cold water ant the tube side hot water are in the same direction and the flow directions are from right to the left side of the figure. Here, it is seen that velocity at the centerline of the shell and tube heat exchanger is increasing and reaches a peak value and then it decreases.

\subsection{Turbulence Kinetic Energy}

Turbulence Kinetic Energy (TKE) indicates the measurement of the turbulence. It is the mean kinetic energy per unit mass associated with eddies in turbulence flow. It is physically measured by root mean square of the velocity fluctuations. Figure 9 indicates the turbulence kinetic energy of the shell and tube heat exchanger. As observed in the figure, the value of TKE is found highest near the baffle zones whereas it gradually decreases apart from segmental baffles. The reason could be explained that due to incorporation of segmental baffles along the flow path, the flow patterns get obstructed and induces higher turbulence intensity.

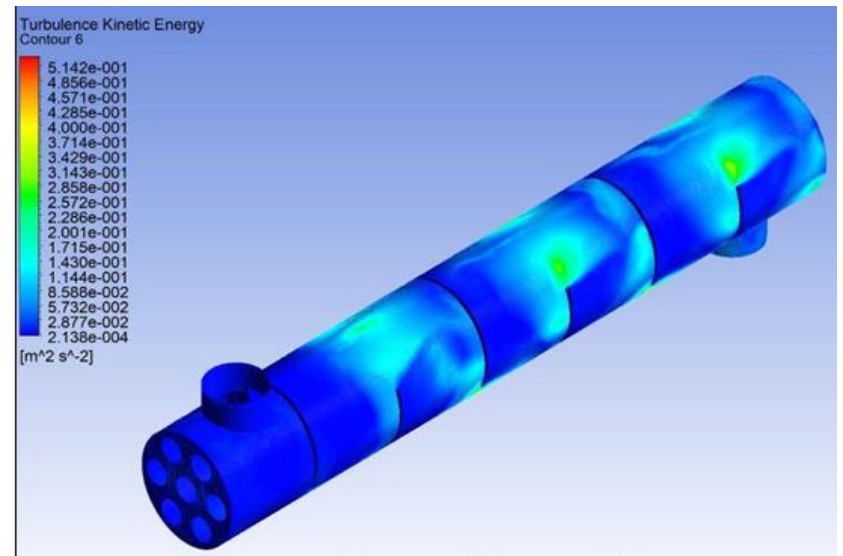

Figure 9: Turbulence variation of shell and tube side water along the flow direction (counter flow)

Figure 10 shows the turbulence kinetic energy along the centerline of the shell and tube heat exchanger. The figure shows that the value of TKE gradually decreases apart from the baffles due to having lower velocity fluctuations. On the contrary when the flow is reaching towards baffles it increases again and reached to the peak value.

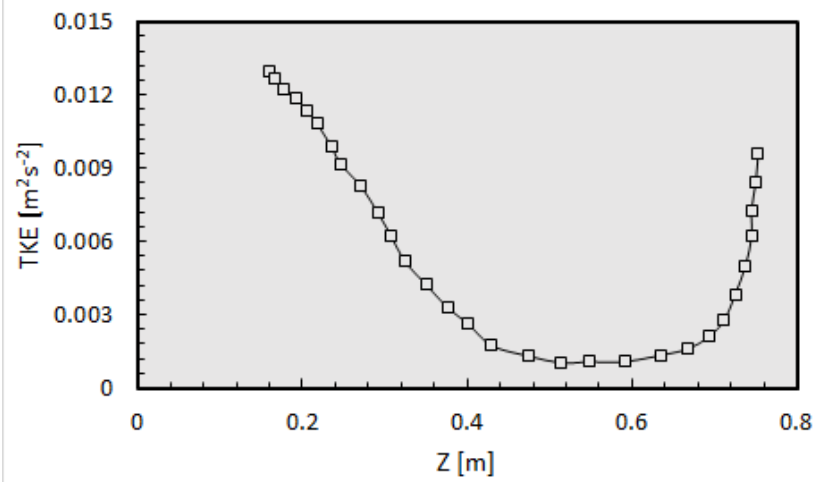

Figure 10: Turbulence variation of shell and tube side water along the centreline (counter flow)

\section{Conclusions}

This project described the CFD analysis of shell and tube heat exchanger by the ANSYS is less costly and flexible process which is efficiently able to determine the performance of the domain. Here, CFD analysis of parallel and counter flow heat exchanger was performed and simulated to understand the heat transfer and the fluid flow regime and conclusion is 
assessed over the better performance of heat transfer during counter flow. In parallel flow, hot water temperature decreased to $339.5 \mathrm{~K}$ from $340 \mathrm{~K}$ and cold water temperature increased to $307.5 \mathrm{~K}$ from $300 \mathrm{~K}$. In counter flow, hot water temperature decreased to $339 \mathrm{~K}$ from $340 \mathrm{~K} \&$ cold water temperature increased to $315 \mathrm{~K}$ from $300 \mathrm{~K}$. So, in counter flow heat exchanger, heat transfer is more than the parallel flow heat exchanger. Following analysis, pressure changed from $3.59 \mathrm{e}+0004$ to $-2.55 \mathrm{e}+0003$. The detailed findings of the temperature, velocities and distribution of pressure can be used as guidance for further optimization of a heat exchanger design. The study shows that CFD modeling can be used to accurately determine the outlet temperature which can be taken as a step for the further collection of the experimental data. This will further help to determine the thermodynamic characteristics of the heat exchanger and can be used for the future design purposes.

The future scope of the study could be expanded to implementing helical baffles which increases heat transfer coefficient while decreasing pressure drop. Moreover, implementation of nanofluids as coolant might a great scope to conduct future investigations as the thermal performances are enhanced due to application of nanofluids. Currently, water based MXene, Functionalized Graphene and hybrid of MXene-Functionalized graphenes nanoparticles are getting attention due to its enormous improvements in thermo-physical properties.

\section{References:}

[1] Hamid Reza Abbasi, EbrahimSharifiSedeh, HosseinPourrahmani and Mohammad HadiMohammadi. Shape optimization of segmental porous baffles for enhanced thermo-hydraulic performance of shell and tube heat exchanger. Applied Thermal Engineering, Vol.: 180, 2020, 115835.

[2] Ravi Gugulothu, NarsimhuluSanke, AVSSKS Gupta and RatnaKumariJilugu (2018). A Review on helical baffles for shell and tube heat exchangers. International Journal of Modern Engineering and Research Technology, Vol.: 5, special issue, June, 2018. ISSN: 2348-8565.

[3] White, F. M. (1986). Fluid mechanics (No. BOOK).McGraw-hill.

[4] Crank, J., \& Nicolson, P. (1947, January). A practical method for numericalevaluationofsolutionsofpartialdifferentialequ ationsof the heat-conduction type. In Mathematical Proceedings of the Cambridge Philosophical Society (Vol. 43, No. 1, pp. 50-67). Cambridge UniversityPress.

[5] Kays,W.,Crawford,M.,\&Weigand,B.(2004).MPf orconvective heat and mass transfer. Bernhard Weigand:McGraw-Hill.
[6] Sellars,J.R.,Tribus,M.,\&Klein,J.(1954).Heattransferto laminar flow in a round tube or flat conduit: the Graetzprobemextended.

[7] Hwang, K. S., Jang, S. P., \& Choi, S. U. (2009). Flow and convective heat transfer characteristics of water-based $\mathrm{Al}_{2} \mathrm{O}_{3}$ nanofluids in fully developed laminar flow regime. International journal of heat and mass transfer, 52(1-2),193199.

[8] Bianco, V., Chiacchio, F., Manca, O., \&Nardini, S. (2009).

Numericalinvestigationofnanofluidsforcedconvectionincircular tubes. Applied Thermal Engineering, 29(17-18),3632-3642.

[9] Akbari, M., Galanis, N., \&Behzadmehr, A. (2011). Comparative analysis of single and two-phase models for CFD studies of nanofluid heat transfer. International Journal of Thermal Sciences, 50(8),1343-1354.

[10] A.E. Quintero, M. Vera and B. Rivero-deAguilar, Wall conduction effects in laminar counterflow parallel-plate heat exchangers,

InternationalJournalofHeatandMassTransfer,70,2014,pp.939953.

[11] M. Vera and A. Linan, Laminar counterflow parallelplate heat exchangers:exact and approximate solutions, International Journal of Heat and Mass Transfer, 53, 2010, pp.4885-4898.

[12] J. Esarte, G. Min, D.M. Rowe, Modelling heat exchangers for thermoelectric generators, J. Power Sources, 93, 2001, pp.72-76.

[13] D.B. Tuckerman, R.F.W. Pease High-performance heat sinking for VLSI IEEE Elect. Device Lett., 2 (5) (1981), pp.126-129.

[14] J.Yu,andH.Zhao,Anumericalmodelforthermoelectricgener ator with the parallel-plate heat exchanger, J. Power sources 172, 2007, pp.428-434

[15] J.Kragh,J.Rose,T.R.Nielsen, andS.Svendsen, Newcoun terflow heat exchanger designed for ventilation systems in cold climates, Energy and Buildings, 39, 2007, pp.11511158

[16] Changhong Zhan, ZhiyinDuan, Xudong Zhao Energy Volume 36, Issue 12, December 2011, Pages6790-6805.

[17] M.I. Hasan, A.A. Rageb, M. Yaghoubi, H. Homayoni Influence of channel geometry on the performance of a counter flow microchannel heat exchanger Int. J. Therm. Sci., 48 (8) (2009), pp. 1607-1618.

[18] Tsung-LinLiu,Ben-

RanFu,ChinPanInternationalJournalofHeat and Mass Transfer Volume 56, Issues 1-2, 1 January 2013, Pages 20 29

[19] T. Tinker, "Shell side characteristics of shell and tube heat exchangers," Gen. Discuss. Heat Transf., no. 1951, pp. 89-116, 1951. 
[20] Gugulothu, R., Sanke, N., \& Gupta, A. V. S. S. K. S. (2019). Numerical study of heat transfer characteristics in shell-and-tube heat exchanger. In Numerical Heat Transfer and Fluid Flow (pp. 375-383). Springer, Singapore.

[21] Reddy, K. V. K., Kumar, B. S. P., Gugulothu, R., Anuja, K., \& Rao, P. V. (2017). CFD analysis of a helically coiled tube in tube heat exchanger. Materials Today: Proceedings, 4(2), 2341-2349.

[22] Fluent, A.N.S.Y.S., 2015. Ansys fluent. Academic Research. Release, 14.

[23] Ahmed, F., Ara, N., Deshpande, V., Mollah, A.S. and Bhowmik, P.K., 2021. CFD validation with optimized mesh using benchmarking data of pebblebed high-temperature reactor. Progress in Nuclear Energy, 134, p.103653.

[24] Gugulothu, R., Sanke, N., Ahmed, F., \&Jilugu, R. K. (2021). Numerical Study on Shell and Tube Heat Exchanger with Segmental Baffle. In Proceedings of International Joint Conference on Advances in Computational Intelligence (pp. 309-318). Springer, Singapore.

[25] Ahmed, F., Abir, M.A., Redwan, A.S.M., Bhuiyan, A.A. and Mollah, A.S., 2021. The impact of D-shaped jaggedness on heat transfer enhancement technique using $\mathrm{Al2O} 3$ based nanoparticles. International Journal of Thermofluids, 10, p.100069.

[26] Ahmed, F., Abir, M.A., Bhowmik, P.K., Deshpande, V. and Mollah, A.S., 2021. Thermohydraulic performance of water mixed Al2O3, $\mathrm{TiO} 2$ and graphene-oxide nanoparticles for nuclear fuel triangular subchannel. Thermal Science and Engineering Progress, 24, p.100929.

[27] Ahmed, F., Abir, M.A., Bhowmik, P.K., Deshpande, V., Mollah, A.S., Kumar, D. and Alam, S., 2021. Computational assessment of thermo-hydraulic performance of Al2O3-water nanofluid in hexagonal rod-bundles subchannel. Progress in Nuclear Energy, 135, p.103700.

[28] HasanKucuk, Murat Unverdi and Mehmet SenanYilmaz. Experimental investigation of shell side heat transfer and pressure drop in a mini channel shell and tube heat exchanger. International Journal of Heat and Mass Transfer, Vol.: 143, 2019, 118493.

\section{Authors CRediT}

Farid Ahmed contributed to validation, data curation, and software. Md Minaruzzaman Sumon contributed to investigation, writing original draft, conceptualization. MuhtasimFuad contributed to resources and visualization. Ravi Gugulothu contributed to resources and visualization. AS Mollah contributed to Writingreviewing \& editing, and supervision.

\section{Creative Commons Attribution License 4.0 (Attribution 4.0 International, CC BY 4.0)}

This article is published under the terms of the Creative Commons Attribution License 4.0 https://creativecommons.org/licenses/by/4.0/deed.en_US 